\title{
Prediction of near field overpressure from quarry blasting
}

\author{
P. Segarra ${ }^{\text {a,* }}$, J.F. Domingo ${ }^{\text {a,b }}$, L.M. López ${ }^{\text {a }}$, J.A. Sanchidrián ${ }^{\text {a }}$, M.F. Ortega ${ }^{\text {a }}$ \\ ${ }^{a}$ Universidad Politécnica de Madrid - E.T.S.I. Minas, Rios Rosas, 21, 28003 Madrid, Spain \\ ${ }^{\mathrm{b}}$ MAXAM Europe, Av. del Partenón, 16, 28042 Madrid, Spain
}

Keywords:

Airblast

Overpressure

Explosive

Scaled distance

Wave reinforcement

Quarry blasting

\begin{abstract}
A B S T R A C T
This paper investigates the propagation of airblast or pressure waves in air produced by bench blasting (i.e. detonation of the explosive in a row of blastholes, breaking the burden of rock towards the free vertical face of the block). Peak overpressure is calculated as a function of blasting parameters (explosive mass per delay and velocity at which the detonation sequence proceeds along the bench) and the polar coordinates of the position of interest (distance to the source and azimuth with respect to the free face). The model has been fitted to empirical data using linear least squares. The data set is composed of 122 airblast records monitored at distances less than $400 \mathrm{~m}$ in 41 production blasts carried out in two quarries. The model is statistically significant and has a determination coefficient of 0.87 . The formula is validated from 12 airblast measurements gathered in five additional blasts.
\end{abstract}

\section{Introduction}

Bench blasting is the most common method of rock excavation in quarries and surface mines. The drilling and blasting cycle consists of drilling one or more rows of blastholes parallel to the free vertical face of the bench and sufficiently close to it to break loose the rock in between [1]. The blastholes are charged with explosives and plugged with crushed rocks or other stemming material. The explosive in each hole is fired and delayed with respect to the others with appropriate initiation systems. The detonation of the explosives breaks and throws the rock mass so that it can be loaded and hauled for further processing or, the case be, for placing in waste dumps. Unfortunately, rock blasting also raises environmental concerns in the form of vibrations and airblast in the vicinity of the blasting sites. In addition to dynamic stresses produced in the ground by seismic waves, airblast waves will impact the walls, roof and windows of nearby structures and may induce damage on them and annoyance to their occupants [1-4]. An accepted starting point to assess the risk of damage consists of comparing the measured peak overpressure (i.e. highest sound pressure above the atmospheric pressure) with the maximum pressure that structural elements can resist [3]. US Bureau of Mines recommendations [2], worldwide used, follow that approach and set a threshold overpressure as function of the frequency response band of the transducers.

\footnotetext{
* Corresponding author. Tel.: +34913 366 454; fax: +34913 366948 . E-mail address: pablo.segarra@upm.es (P. Segarra).
}

Although peak overpressures from rock blasting are usually well below compliance values, the major drawback of airblast is that the induced noise may lead to buildings occupants to believe that permanent damage may have occurred [4]. The knowledge of the parameters with a major influence on peak overpressure is a useful guide to keep airblast at acceptable levels and reduce neighbours claims. This paper provides a new prediction formula of the peak overpressure based on blasting and airblast data gathered in 41 blasts monitored in two quarries. The data set is composed of 122 airblast events monitored around the blasted blocks at distances less than $400 \mathrm{~m}$. Measurements from five more blasts are used to evaluate the predictive ability of the model.

\section{Background}

In rock blasting, the sources of pressure waves in air are [2]:

- Rock displacement of the vertical face and ground swelling in the blasthole collar.

- Vertical component of ground vibrations.

- High pressure detonation gasses venting through cracks.

- High pressure detonation gasses escaping from the blown out stemming.

The pressure waves produced by each of these mechanisms are known as: air pressure pulse, rock pressure pulse, gas release pulse and stemming release pulse, respectively. Air pressure pulse and rock pressure pulse are unavoidable airblast sources in bench 
blasting, whereas both gas release pulse and stemming release pulse can be avoided through the blast design [4]. These last two mechanisms produce high frequency waves superposed to the air pressure pulse, and are the main source of annoyance nearby the blasting site. The rock pressure pulse has the smallest amplitude of airblast components and its contribution to total airblast can be considered negligible [1].

The combination of those four mechanisms produces a series of pressure waves, which maximum amplitude is predicted from the properties of airblast waves [1,3,5]. The detonation of different sized charges with similar geometry and of the same explosive in an isotropic medium (i.e. flat ground surface and identical atmosphere conditions) produces self-similar blast waves at identical scaled distances $Z$. This dimensional parameter is defined as [5]:

$Z_{M}=R / M^{1 / 3}$

or

$Z_{E}=R / E^{1 / 3}$

where $R$ is the distance from the centre of the explosive source, $M$ is the explosive mass, and $E$ is the energy of the explosive.

For small pressures, the peak overpressure is linearly related to the scaled distance in a log-log-scale [1]:

$P=a_{0} Z^{a_{1}}$

where $a_{0}$ and $a_{1}$ are coefficients of the model, and $Z$ is the scaled distance calculated with either Eqs. (1), or (2).

Eq. (3) with $Z$ calculated from Eq. (1) as $Z_{M}$ is widely used in surface blasting $[2,4,6,7]$. The coefficients $a_{0}$ and $a_{1}$ are calibrated for each site by fitting Eq. (3) to empirical data. They can be considered as fitting constants that lump the influence of other variables not included explicitly in Eq. (3) [7]. Table 1 gives $a_{0}$ and $a_{1}$ values for a wide range of blasting conditions. It also lists the main characteristics of the blasts and the lower frequency limit of air transducers.

Table 1 shows that the coefficient $a_{0}$ has a large variability, nearly three orders of magnitude, which confirms that there are a number of variables that influence this coefficient. The scatter in the $a_{0}$ coefficients reported by USBM [2] is an example of the directionality of the propagation of blast waves. In fact, the contour curves of equal overpressures from bench blasting have a shape similar to an "egg" curve, longer at the floor level and shorter at the top [7-12]. These azimuthal variations may be reinforced in specific directions depending on the characteristics of the

Table 1

Coefficients ( $a_{0}$ and $a_{1}$ ) of peak overpressure attenuation laws function of mass-scaled distances.

\begin{tabular}{|c|c|c|c|c|}
\hline Source & Description of the tests & $\begin{array}{l}f_{L}^{a} \\
(\mathrm{~Hz})\end{array}$ & $\begin{array}{l}a_{0}(\mathrm{~Pa} \\
\left.\left[\mathrm{m} \mathrm{kg}^{-1 / 3}\right]^{-\mathrm{a} 1}\right)\end{array}$ & $a_{1}$ \\
\hline \multirow[t]{3}{*}{ USBM [2] } & Quarry blasts. Behind face & 0.1 & 622 & -0.515 \\
\hline & $\begin{array}{l}\text { Quarry blasts. Direction of } \\
\text { initiation }\end{array}$ & 0.1 & 19,010 & -1.12 \\
\hline & Quarry blasts. Front of face & 0.1 & 22,182 & -0.966 \\
\hline \multirow[t]{2}{*}{ ISEE [4] } & $\begin{array}{l}\text { Confined blasts for airblast } \\
\text { suppression }\end{array}$ & n.s. ${ }^{b}$ & 1906 & -1.1 \\
\hline & $\begin{array}{l}\text { Blasts with average burial } \\
\text { of the charge }\end{array}$ & n.s. & 19,062 & -1.1 \\
\hline \multirow[t]{3}{*}{$\begin{array}{l}\text { Kuzu et al. } \\
{[6]}\end{array}$} & $\begin{array}{l}\text { Quarry blasts in competent } \\
\text { rocks }\end{array}$ & 2 & 261.54 & -0.706 \\
\hline & Quarry blasts in weak rocks & 2 & 1833.8 & -0.981 \\
\hline & Overburden removal & 2 & 21,014 & -1.404 \\
\hline $\begin{array}{l}\text { Hustrulid } \\
\text { [7] }\end{array}$ & $\begin{array}{l}\text { Detonations in air. } \\
\text { Unconfined }\end{array}$ & n.s. & 185,000 & -1.2 \\
\hline
\end{tabular}

${ }^{a} f_{L}$ : lower frequency limit of the transducers.

b n.s.: not specified. sequence of the blast $[2,10,13]$. The influence of the rock type on the peak overpressure is apparent from the differences in $a_{0}$ values given by Kuzu et al. [6]. The effect of charge confinement is shown by the dispersion of $a_{0}$ from ISEE data [4], and most significantly by the high value reported by Hustrulid [7] from shots of unconfined charges. This is consistent with other works $[1,2]$.

Conversely, the variability of $a_{1}$ is moderate, which indicates that the influence of distance and charge is in general relatively well described by this coefficient. Atmospheric conditions also play an important role in the attenuation of airblast; they are more relevant in the far field than in the near field $[1,2,10]$.

Some of the above mentioned variables are considered together with the scaled distance to predict peak overpressures by a number of references in the literature $[9,10,12,13]$.

\section{Description of the database}

The database used to build the model is composed from measurements in two quarries located in the South-East of the province of Madrid (Spain): El Alto (indentified as quarry A) and Monte Espartinas (identified as quarry B). Data arise from one single shot and 30 production blasts in quarry A [12], and from 15 more blasts in quarry $B$. The characteristics of these blasts and of the airblast measurements are summarized next.

\subsection{Characteristics of the blasts}

Fig. 1 shows an isometric and a plan view of a blast that is representative of the techniques used in both sites; it also defines the most relevant blast parameters. Rosenthal and Morlock [14] describe the parameters with a major influence in airblast from surface coal blasting. These are: geological factors (type and thickness of overburden), geometrical parameters (burden and spacing), charging characteristics (stemming length and type, charge weight per delay, and charge depth below ground surface), timing (delay interval, direction of initiation), and meteorological conditions. The relative importance of those parameters is site specific and a definitive ranking cannot be provided [4].

To describe the conditions in which the tests were carried out, Tables 2 and 3 show the rock properties and blast characteristics, respectively. The powder factors (i.e. explosive mass per unit volume of blasted rock) that show the response of the rock mass to the blasting activity [15] are included in Table 3. They are in line with the recommended values for rocks with good and fair blast behaviour, 0.3 and $0.45 \mathrm{~kg} / \mathrm{m}^{3}$, respectively [16]. The range of the main design ratios, such as burden/blasthole diameter $(B / d)$, bench height/burden $(H / B)$, spacing between holes/burden $(S / B)$, and stemming length/burden $(T / B)$ are shown in Table 4 . They are compared with the standards for preliminary blast design with vertical drilling [7,17], which are also given in Table 4 . The blast design in $53 \%$ of the blasts is made according to those standards. In the rest of the blasts, one of the blasting ratios, mainly $H / B$ or $T / B$ in quarry $A$ and $B / d$ in quarry $B$, is outside the suggested range. The existence of a loose overburden of sandy nature and little cohesion in quarry $\mathrm{A}$ is the reason for blasting in higher benches with longer stemming lengths than usual. The use of fairly inclined blastholes in quarry B allows longer burdens than those given by the standards for vertical blastholes. The results of the blasts in terms of toe breakage, face control, fragmentation, and muckpile characteristics are qualitatively ranked as good in all the blasts.

\subsection{Airblast overpressure measurements}

Dynamic overpressure in air was monitored with linear $L$ type microphones connected to the airblast channels of recording units 


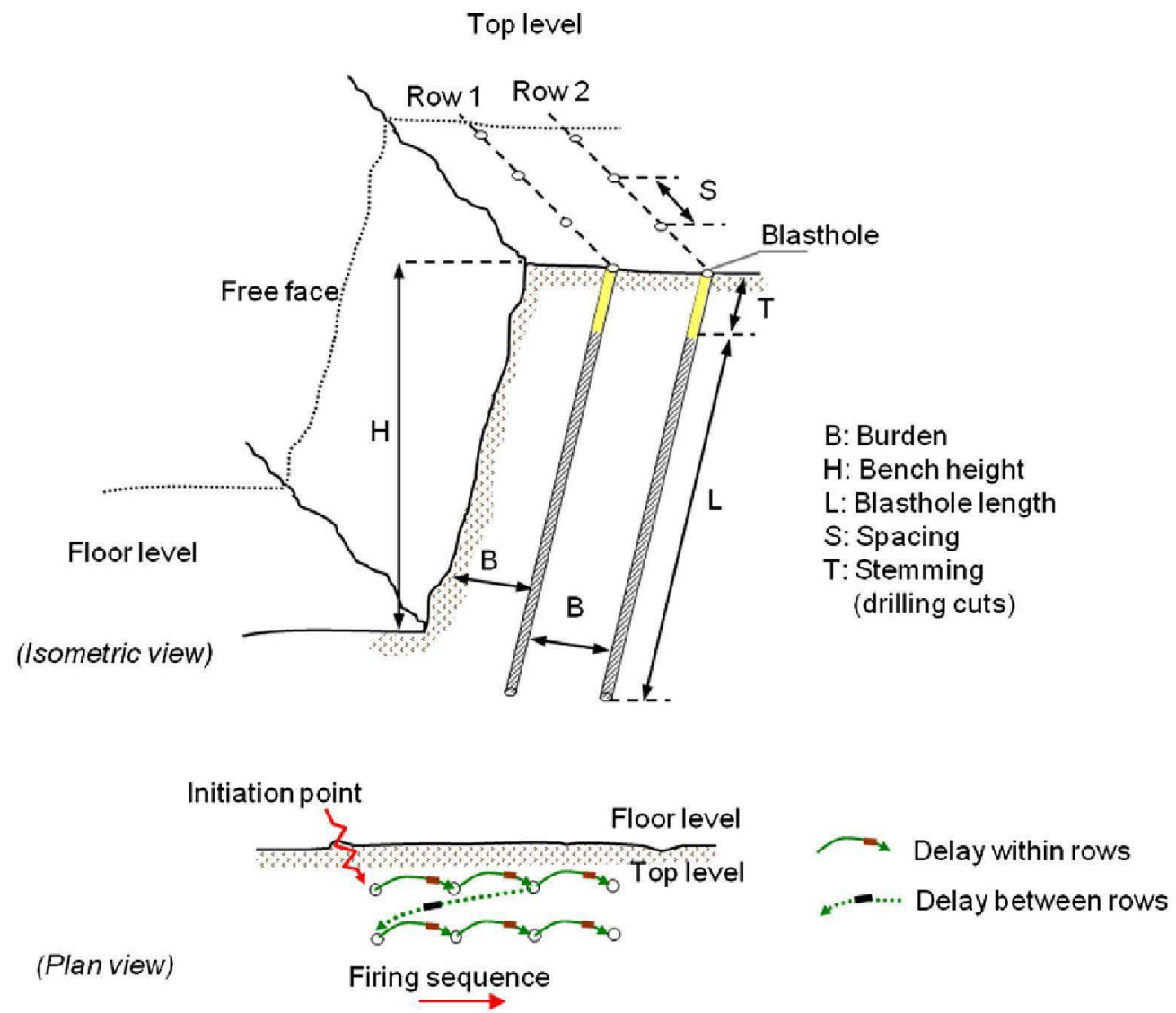

Fig. 1. Sketch of a typical blast.

Table 2

Rock characteristics.

\begin{tabular}{lll}
\hline Parameters & Quarry A & Quarry B \\
\hline Rock type & $\begin{array}{l}\text { Clayish-marl overburden (4-6 m } \\
\text { thick) and limestone }\end{array}$ & $\begin{array}{l}\text { Gypsum with clay } \\
\text { intercalations } \\
\text { Rock density, } \\
\mathrm{kg} / \mathrm{m}^{3}\end{array}$ \\
$\begin{array}{c}\text { Tensile } \\
\text { strength, } \\
\text { MPa }\end{array}$ & 7.6 & 2200 \\
$\begin{array}{c}\text { Qualitative rock } \\
\text { strength }\end{array}$ & Low-intermediate & - \\
\hline
\end{tabular}

manufactured by Vibra-Tech and Instantel. The other channels of the units were occupied by geophones. Air overpressures were measured in a range from 0.5 to $500 \mathrm{~Pa}$ with a resolution of $0.25 \mathrm{~Pa}$. The microphones have an operating frequency response from 2 to $250 \mathrm{~Hz}$, which is adequate to measure accurately overpressures in the frequency range critical for structures and in the range of frequencies critical for human hearing $[2,18]$. The accuracy of airblast devices is $\pm 10 \%$ or $\pm 1 \mathrm{~dB}$ between 4 and $125 \mathrm{~Hz}$, whichever is larger [19]. The recording units are triggered when the particle velocity in the ground exceeds $0.5 \mathrm{~mm} / \mathrm{s}$. Other setups used were: sample rate of 1024 samples per second, continuous record mode of the full waveform, and automatic stop mode (the unit stops recording $2 \mathrm{~s}$ after the particle velocity falls below the trigger level).

The microphones provided with a foam windshield were mounted at a height of $1 \mathrm{~m}$ above the floor and oriented visually towards the blast. This is enough to get accurate recordings [20]. The distance from the microphones to the gravity centre of the blasts ranged from 45 to $394 \mathrm{~m}$, with mean and standard deviation (following the \pm symbol) of $97.7 \pm 71.0 \mathrm{~m}$ in quarry $A$ and $204.6 \pm 80.5 \mathrm{~m}$ in quarry B. Meteorological conditions are expected to have little influence in peak overpressures at these distances $[4,10]$. The sensors were placed either in the top level, in the bottom level or in both. When multiple microphones were used in the same blast, they were placed in different positions in quarry $A$ and very close each other in quarry $B$ (i.e. the distance between microphones was $20 \mathrm{~cm}$ ).

The reference system used to locate the measuring stations is based on that given by Griffiths et al. [8] and shown in Fig. 2; the pole is the gravity centre of the blast and the polar axis is drawn perpendicularly to the line that joins the first and last blastholes, towards the bench floor. The coordinates for each microphone position are $(R, \theta)$, where $R$ is the distance from the pole to the microphone and $\theta$ is the angle from the polar axis towards the first hole nominally fired (in the single shot, $\theta$ is counted clockwise). The position of all sensors is shown in Fig. 2; the points are differentiated for site $A$ and $B$.

In $20 \%$ of the blasts there was a limited stemming ejection that produced an additional strong wave in air (i.e. stemming release pulse). The range of measured peak overpressures are 6-482 Pa in quarry $\mathrm{A}$ and $12.2-148 \mathrm{~Pa}$ in quarry $\mathrm{B}$. Peak overpressures versus mass-scaled distance calculated with Eq. (1) are plotted in Fig. 3. Plain mass data have been used in the calculation of scaled distances, without any conversion to a reference explosive; a similar relation with the overpressure is obtained if the distance is normalized by the energy of the explosive as in Eq. (2), or if the explosive mass is converted to an equivalent mass of a standard explosive. Straight mass has been used since it can be readily obtained in the field; this matter is revisited in Section 5. The data 
Table 3

Blasting characteristics: drilling, charging and timing.

\begin{tabular}{|c|c|c|c|c|c|}
\hline \multirow[t]{3}{*}{ Parameters } & \multicolumn{3}{|c|}{ Quarry A } & \multicolumn{2}{|l|}{ Quarry B } \\
\hline & \multirow[t]{2}{*}{$\mathrm{SS}^{\mathrm{a}}$} & \multicolumn{2}{|c|}{ Production blasts } & \multicolumn{2}{|c|}{ Production blasts } \\
\hline & & Mean \pm std & Range & Mean \pm std & Range \\
\hline Hole diameter $(d), \mathrm{mm}$ & 155 & 142 & - & 89 & - \\
\hline No of rows & 1 & 1 & - & - & $1-3$ \\
\hline Bench height $(H), \mathrm{m}$ & 20.2 & $17.2 \pm 1.3$ & $15.6-19.9$ & $7.2 \pm 1.5$ & $4.8-10.1$ \\
\hline Blasthole inclination, ${ }^{\circ}$ & 6 & 6 & - & 20 & - \\
\hline Burden $(B), \mathrm{m}$ & 5 & $4.8 \pm 0.4$ & $3.9-5.5$ & $3.5 \pm 0.4$ & $2.9-4.0$ \\
\hline Spacing between blastholes $(S), \mathrm{m}$ & - & $6.0 \pm 0.5$ & $4.5-6.6$ & $3.8 \pm 0.4$ & $3.0-4.2$ \\
\hline Mass of expl. detonated in a delay $(M), \mathrm{kg}$ & 280 & $194 \pm 42.8$ & $107-284$ & $55.2 \pm 29.7$ & 21.3-118.8 \\
\hline Energy (heat of explosion) in a delay $(E)$, MJ & 1355 & $873 \pm 246$ & $486-1391$ & $217 \pm 117$ & $83.4-466$ \\
\hline Stemming length $(T), \mathrm{m}$ & 5.1 & $4.4 \pm 0.8$ & $3.0-6.4$ & $1.8 \pm 0.1$ & $1.5-2.0$ \\
\hline Powder factor, $\mathrm{kg} / \mathrm{m}^{3}$ & - & $0.40 \pm 0.06$ & $0.28-0.49$ & $0.40 \pm 0.07$ & $0.30-0.51$ \\
\hline Delay within rows, ms & - & $58 \pm 22$ & $17-84$ & 25 & - \\
\hline Delay between rows, ms & - & - & - & $161 \pm 28.6$ & $100-192$ \\
\hline Firing velocity down the face $\left(V_{l}\right), \mathrm{m} / \mathrm{s}$ & - & $134 \pm 103$ & $67-383$ & $151 \pm 14$ & $120-168$ \\
\hline Explosive types ${ }^{\mathrm{b}}$ & \multicolumn{3}{|c|}{$G+\{A, A L, E, H A L$ or $L A\}$} & \multicolumn{2}{|c|}{$\mathrm{G}+\mathrm{A}$} \\
\hline In-hole and surface initiation systems & \multicolumn{3}{|c|}{ Non-electric caps/electronic caps } & \multicolumn{2}{|c|}{ Non-electric caps } \\
\hline
\end{tabular}

a $\mathrm{SS}=$ single blasthole shot.

b G: gelatine, A: standard ANFO, AL: aluminized ANFO, E: 80/20 emulsion/ANFO blend, HAL: high density aluminized ANFO, and LA: low density ANFO.

Table 4

Range of design ratios in production blasts.

\begin{tabular}{llll}
\hline Ratios & Standard [7,17] & Quarry A & Quarry B \\
\hline Burden/blasthole diameter $(B / d)$ & $20-40$ & $27-39$ & $33-45$ \\
Bench height/burden $(H / B)$ & $\mathbf{1 . 2 5 - 4}$ & $3-4.7$ & $1.8-2.9$ \\
Spacing/burden $(S / B)$ & $\mathbf{1 - 2}$ & $0.94-1.56$ & $0.8-1.38$ \\
Stemming length/burden $(T / B)$ & $0.5-1$ & $0.6-1.4$ & $0.5-0.7$ \\
\hline
\end{tabular}

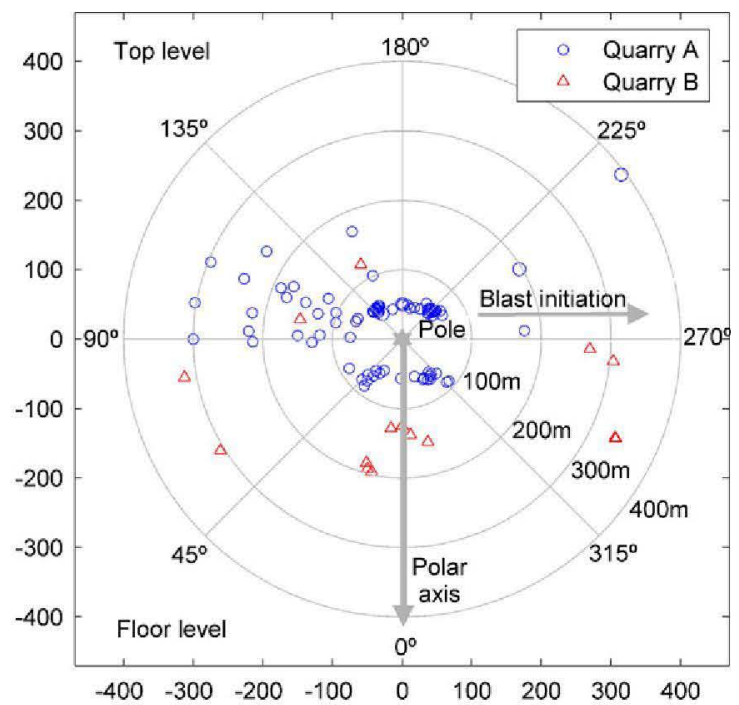

Fig. 2. Reference system and sensor location (distances in $\mathrm{m}$ ).

in Fig. 3 is differentiated as function of the site, blasting type (production blast and single shot) and position (top and floor levels of the block to be blasted).

\subsubsection{Uncertainty of peak overpressure measurements}

The uncertainty of the peak overpressure $(\delta P / P)$ is assessed from the ratio of the standard deviation of the mean (i.e. standard deviation divided by the square root of the measurements) to the mean of the overpressures measured in the same blast with microphones positioned right next to one another. $\delta P / P$ cannot be calculated in

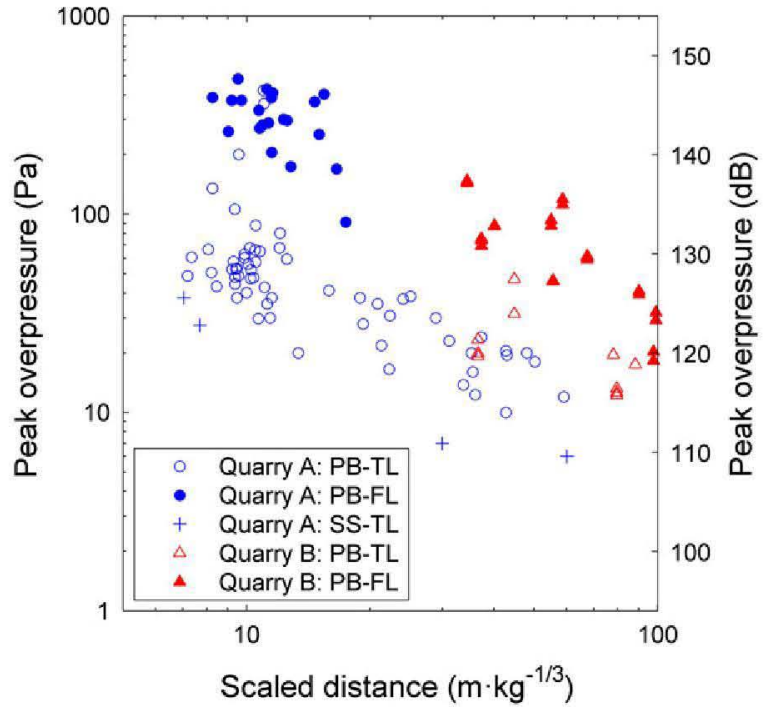

Fig. 3. Peak overpressure versus scaled distance (PB: production blast, SS: single shot, TL: top level, and FL: floor level).

quarry A, since the positions of the microphones used in each of the blasts were quite different. In quarry $B$ the range of relative uncertainties varies from $0.3 \%$ to $19.7 \%$. This set of uncertainties is used to calculate the standard error of the measurement. Because the errors are positive, the population of relative uncertainties could follow a lognormal distribution; this hypothesis is confirmed with the Lilliefors normality test applied to the logarithms of $\delta P / P$. The maximum likelihood estimates (MLEs) for the mean and standard deviation of that distribution are calculated from the sample of relative uncertainties. The 95\% upper value of the distribution of relative uncertainties calculated from these MLEs is $13.1 \%$. This value is an estimation of the relative standard error or relative expanded uncertainty of peak overpressures [21].

\section{Description of the model}

In order to account for asymmetrical propagation of airblast around the bench, a new parameter $A$ is considered: 
$P=A Z^{a}$

$A$ being an asymmetry correction factor that is defined as the product of:

- a coefficient $a_{0}$,

- a bench face factor, $A_{f}$ that considers the influence of the azimuth of the measurement point with respect to the bench face, and

- an initiation sequence factor, $A_{s}$ that accounts for the effect of the blast initiation (i.e. initiation direction, delay between blastholes and relative position between blastholes along the face).

Replacing $A$ in Eq. (4) leads to:

$P=a_{0} A_{f} A_{s} Z^{a_{1}}$

The rock displacement at the bench face is the main source of airblast in properly designed blasts in which the explosive is well confined [2]. This leads, for a given scaled distance, to higher overpressures in front of the face and smaller behind it. In order to account for this directional effect, the factor $A_{f}$ amplifies the overpressure $a_{0} z^{a 1}$ in the bench floor level and attenuates it in the top one. Functions like: $1+a_{2} \cos \theta, 1 /\left(1-a_{2} \cos \theta\right)$ or $\exp \left(a_{2^{-}}\right.$ $\cos \theta$ ), with $a_{2}$ a positive coefficient, could be used with similar results; the first function type was used by Griffiths et al. [8]. They are positive for all $\theta$ and are maximum at $\theta=0$ (i.e. in front of the face) and minimum at $\theta=180^{\circ}$ (i.e. behind the face). In our case, for convenience in the model fitting, the exponential form has been chosen:

$A_{f}=\exp \left(a_{2} \cos \theta\right)$

The detonation of the explosive in each blasthole produces a pulse of air waves that may interact with the waves from nearby blastholes depending of the blast sequence and propagation path $[2,10,13]$. If the initiation of the blast proceeds at a velocity close to the speed of sound, the wave generated from the detonation in a hole will reach the next hole in the sequence at about the same time that it detonates, resulting in a reinforcement of the airblast in the direction of initiation. This overlapping can also take place at subsonic velocities of initiation, with diminishing effect as initiation is slower. Siskind et al. [2] suggest that the initiation velocity be less than half the speed of sound in order to prevent airblast reinforcement in the direction of initiation. For propagation paths in an opposite direction to the blast initiation (i.e. $\theta=90^{\circ}$, see Fig. 2), the blast waves from a newly detonated hole never reaches the waves from previous ones, independently of the initiation velocity. Snell and Oltmans [22] examined the supersonic range of initiation velocities in the direction parallel to the row of blastholes. They concluded that in such direction reinforcement would not occur for initiation velocities higher than 1.89 times the speed of sound. Air wave reinforcement can take place at initiation velocities in excess of that figure in directions other than the direction of blastholes initiation (i.e. directions on which the projection of the initiation velocity is approximately sonic). It should be noted, however, that highly supersonic initiation along the face is unusual in quarry blasting since it encompasses short delay times which are disfavored for rock fragmentation performance and ground vibration, see for instance [23]. In our data, the initiation velocity goes from 67 to $383 \mathrm{~m} / \mathrm{s}$ (see Table 3); the latter is a fairly high value in quarry blasting.

The initiation sequence factor $A_{s}$, that accounts for the wave superposition in the direction of initiation has been defined as follows:

$A_{\mathrm{s}}=\exp \left(a_{3} W_{o}\right)$ where $W_{o}$ is a function of the angle and the velocity of initiation so that $A_{s}$ is maximum in the direction of initiation and for velocities of initiation around the speed of sound, and minimum in directions opposite the initiation one and at initiation velocities below half the speed of sound:

$W_{\circ}=\frac{1}{1+\lambda_{1} e^{-\lambda_{2} v_{I}}}(1-\sin \theta)$

The first part of $W_{0}$ is a logistic function of the initiation velocity relative to the speed of sound $v_{I}=V_{I} / \mathrm{c}$; the parameters $\lambda_{1}$ and $\lambda_{2}$ are selected so that the logistic function be 0.01 for $v_{1}=0.5$ and 0.99 for $v_{I}=1: \lambda_{1}=9.703 \times 10^{5}$ and $\lambda_{2}=18.380$. Note that, should initiation velocities be much higher than the speed of sound, a bell-like or band-pass filter-type function should be required instead, with an upper cut-off value (at relative initiation velocities of about 1.89 ) at which wave reinforcement no longer happens in the direction of initiation. In this case, other directions of reinforcement (on which the projected initiation velocity is approximately sonic) appear. Since in our data the maximum relative initiation velocity is $v_{I}=1.13$, such upper cut-off is not required and only the direction of initiation $\left(\theta=270^{\circ}\right)$ bears the maximum pressure reinforcement, as shown by the term $(1-\sin \theta)$.

Replacing $A_{f}$ from Eq. (6) and $A_{s}$ from Eq. (7) in Eq. (5) leads to an overpressure function of three variables $\left(Z, \cos \theta\right.$ and $\left.W_{o}\right)$ with four coefficients $\left(a_{0}, a_{1}, a_{2}\right.$ and $\left.a_{3}\right)$ :

$P=a_{0} Z^{a_{1}} \exp \left(a_{2} \cos \theta+a_{3} W_{o}\right)$

Taking natural logarithms in Eq. (9) gives the linear function:

$\log P=\log a_{0}+a_{1} \log Z+a_{2} \cos \theta+a_{3} W_{o}$

\section{Results and discussion}

Eq. (10) is fitted to the data set using ordinary least squares. The overpressure is given in Pascals. The scaled distance is calculated with Eq. (1) as function of the explosive mass detonated in a delay. The relative initiation velocity is obtained using a velocity of sound of $338 \mathrm{~m} / \mathrm{s}$ that is calculated from the average conditions of the tests (i.e. temperatures around $20^{\circ} \mathrm{C}$ and a $650 \mathrm{~m}$ height). The coefficients of the regression and their main statistics are given in Table 5 . The low $p$-values of the coefficient estimates are strong evidence that the model is statistically valid. The adjusted determination coefficient of the fitted model $R_{a}^{2}$ (best indicator of the fit quality in multiple regression) is 0.87 ; the goodness of the fit does not change whether $Z_{E}$ or $Z_{M}$ is used. If Eq. (10) without the last addend (i.e. the initiation sequence factor $A_{s}$ is removed from the model) is fitted to the data, $R_{a}^{2}$ decreases to 0.78 , dropping to 0.21 when both $A_{f}$ and $A_{s}$ are removed from the model, i.e. only the scaled distance is used as predictor, Eq. (3). The scatter in the data is apparent from Fig. 3.

A plot of the measured peak overpressures versus the predicted ones with our model is given in Fig. 4; the data are differentiated as

Table 5

Coefficients of the linear least squares regression.

\begin{tabular}{lllccl}
\hline Coefficient & Mean & $\mathrm{SE}^{\mathrm{a}}$ & $p$-Value $^{\mathrm{b}}$ & \multicolumn{2}{c}{ Conf. interval 95\% $^{n}$} \\
\cline { 5 - 6 } & & & & Min. & Max. \\
\hline $\log a_{0}$ & 6.953 & 0.1465 & $<0.0001$ & 6.663 & 7.243 \\
$a_{0}$ & 1046 & & & 782.9 & 1398 \\
$a_{1}$ & -0.962 & 0.0461 & $<0.0001$ & -1.05 & -0.870 \\
$a_{2}$ & 1.25 & 0.0522 & $<0.0001$ & 1.14 & 1.35 \\
$a_{3}$ & 1.09 & 0.119 & $<0.0001$ & 0.852 & 1.32 \\
\hline
\end{tabular}

a SE: standard error of the regression coefficients estimates.

b $p$-Value for the $t$-statistic applied to the regression coefficients estimate. 

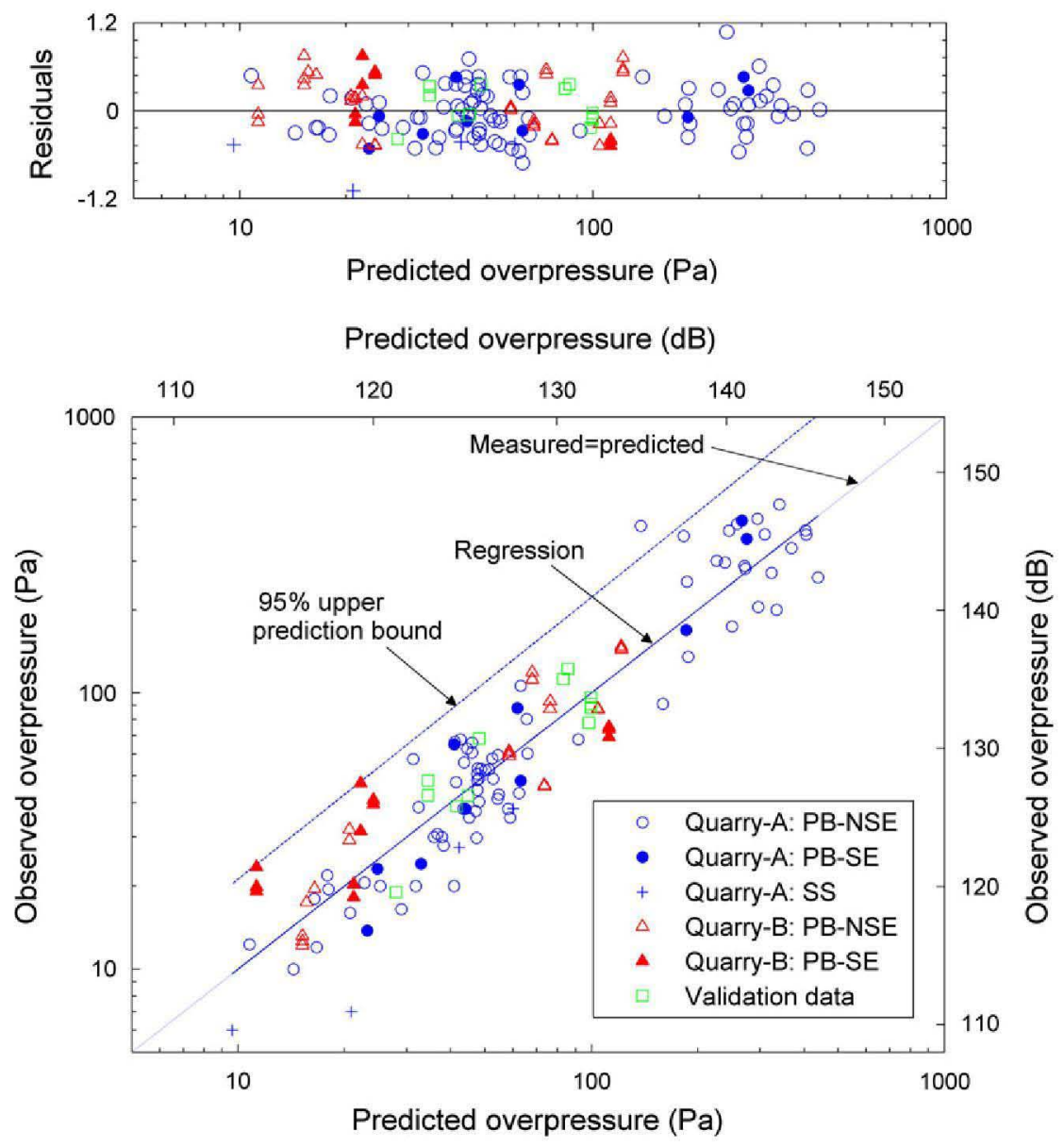

Fig. 4. Measured versus predicted peak overpressures (PB: production blast, SS: single shot, NSE: no stemming ejection, and SE: stemming ejection) and residuals of the fit.

function of the site, blast type and existence of stemming ejection. The regression line has a slope of one with a zero constant term. The fact that overpressures from the single blasthole shot are below the regression line is consistent with the effect of the volume of displaced rock on airblast [4], since a single blasthole moves less volume of rock compared with a delayed production blast. Fig. 4 also shows that the upper prediction band at a $95 \%$ confidence level is a safe rank for blasts with stemming ejections.

The residuals of the fit $r_{i}$ (i.e. $\log P_{i}-\log P_{i}^{*}$ ) are also plotted in Fig. 4 . The hypotheses that the residuals are normally distributed with a constant variance are confirmed at a $95 \%$ confidence level by means of the Lilliefors and Brown-Forsythe tests. The relative error between the measured $i$ th overpressure $\left(P_{i}\right)$ and the predicted one $\left(P_{i}^{*}\right)$ is given by:

$R E_{i}=P_{i} / P_{i}^{*}-1=\exp \left(r_{i}\right)-1$

The mean of the absolute values of the relative errors of our data set is $32 \%$. This value is a measure of the accuracy between measured and predicted overpressures. Data from two new blasts carried out in quarry A and three additional blasts made in quarry $B$ are used to assess the predictive capability of the model. The recorded peak overpressures are also shown in Fig. 4; these new points are within the cloud of data used to build the prediction formula. The basic characteristics of the shots (the powder factor is

Table 6

Prediction characteristics of the model.

\begin{tabular}{|c|c|c|c|c|c|c|c|c|c|}
\hline \multirow[t]{2}{*}{ Site } & \multirow[t]{2}{*}{ Blast } & \multicolumn{5}{|c|}{ Measurements } & \multicolumn{2}{|c|}{ Predictions $^{\mathrm{b}}$} & \multirow{2}{*}{$\begin{array}{l}\text { Errors } \\
\text { RE (\%) }\end{array}$} \\
\hline & & $P F^{\mathrm{a}}\left(\mathrm{kg} / \mathrm{m}^{3}\right)$ & $V_{1}(\mathrm{~m} / \mathrm{s})$ & $Z\left(\mathrm{~m} / \mathrm{kg}^{1 / 3}\right)$ & $\theta\left({ }^{\circ}\right)$ & $P(\mathrm{~Pa})$ & $P^{*}(\mathrm{~Pa})$ & $P_{95}^{*}(\mathrm{~Pa})$ & \\
\hline \multirow[t]{4}{*}{ A } & $\# 1$ & - & 89.6 & 10.7 & 130 & 68.3 & 48.2 & 90.0 & 41.6 \\
\hline & \#2 & - & 94.0 & 7.5 & 243 & 122 & 85.6 & 160.0 & 42.5 \\
\hline & & - & 94.0 & 7.5 & 193 & 42.3 & 44.8 & 83.9 & -5.5 \\
\hline & & - & 94.0 & 7.5 & 110 & 77.8 & 98.4 & 183.9 & -20.9 \\
\hline \multirow[t]{8}{*}{ B } & \#3 & 0.38 & 160 & 127.5 & 356 & 48 & 34.5 & 65 & 39.2 \\
\hline & & 0.38 & 160 & 127.5 & 356 & 42.5 & 34.5 & 65 & 23.2 \\
\hline & $\# 4$ & 0.40 & 164.0 & 50.0 & 11 & 112.3 & 83.2 & 155.6 & 34.9 \\
\hline & & 0.40 & 164.0 & 86.3 & 32 & 38.8 & 41.5 & 77.9 & -6.6 \\
\hline & & 0.40 & 164.0 & 123.6 & 36 & 19.0 & 28.0 & 52.7 & -32.3 \\
\hline & \#5 & 0.28 & 172.0 & 42.3 & 6 & 96.0 & 99.7 & 186.3 & -3.7 \\
\hline & & 0.28 & 172.0 & 42.3 & 6 & 90.8 & 99.7 & 186.3 & -8.9 \\
\hline & & 0.28 & 172.0 & 42.3 & 6 & 88.2 & 99.7 & 186.3 & -11.5 \\
\hline
\end{tabular}

a $P F$ : powder factor.

${ }^{\text {b }} P^{*}$ : predicted peak overpressure and $P_{95}^{*}: 95 \%$ upper prediction bound of peak overpressure. 
not available for blasts in quarry $A$ and is not given), the predicted peak overpressure and the relative prediction errors calculated with Eq. (11) are shown in Table 6. The absolute value of these errors is ranged from $3.7 \%$ to $42.5 \%$, with mean of $22.6 \%$. The upper prediction bound of the peak overpressure at a confidence level of $95 \%$ is also given in Table 6. These values are at least a $131 \%$ greater than the measured overpressure.

Data gathering in a production environment such as quarry blasting makes it difficult the design of experiments so that spurious relations between variables may occur. The predictors of the model: $\log Z, \cos \theta$, and $W_{o}$ are weakly correlated among themselves; the hypothesis of correlation cannot be rejected and the absolute values of the Pearson coefficients vary from 0.2 to 0.4 . The consequences of these inter-correlations in the linear regression are investigated from the variance inflation factors $(V I F)$ of the predictors, which are 1.21 for $\log Z, 1.22$ for $\cos \theta$, and 1.07 for $W_{o}$; such VIF values close to unity indicate no influence of their inter-correlation on the multiple regression [24].

Fig. 5 shows a plot of the factor $A=a_{0} A_{f}, A_{s}=a_{0} \exp \left[a_{2} \cos \theta+a_{3^{-}}\right.$ $\left.W_{o}\left(\theta, v_{l}\right)\right]$ as a function of its two variables, $\theta$ and $v_{l}$. The factor $A$ varies from 302.9 to $16,045 \mathrm{~Pa} \mathrm{~m} \mathrm{~m}^{0.962} \mathrm{~kg}^{-0.321}$; the lower bound is obtained behind the face (i.e. $\theta=180^{\circ}$ ) for relative velocities equal to 0.5 , and the largest for measurements in front of the face (i.e. $\theta=319^{\circ}$ ) from blasts with sonic initiation velocities. This range agrees quite well with the highest and smallest values of the coefficient $a_{0}$ obtained from fitting Eq. (3) to empirical data from quarry blasts with confined charges, see the coefficients in Table 1 for Refs. $[2,4,6]$.

Contour maps of equal overpressure $P$ show by inspection the main propagation features in one area $[9,10]$. Fig. 6 shows, as a matter of example, the effect of the firing velocity in the propagation of blast waves. The contours of peak overpressure equal to 89.3 Pa (limit established by US Bureau of Mines [2] for linear type microphones) are plotted for blasts with constant explosive mass in a delay of $149 \mathrm{~kg}$ (mean value from the 41 blasts) and different firing velocities along the face.

The knowledge of the maximum likely peak overpressure $\left(P_{\max }\right)$ from a given blast at a certain position is useful to avoid damage and also for control purposes. Such value is estimated as the upper prediction bound of the peak overpressure at a $95 \%$ confidence

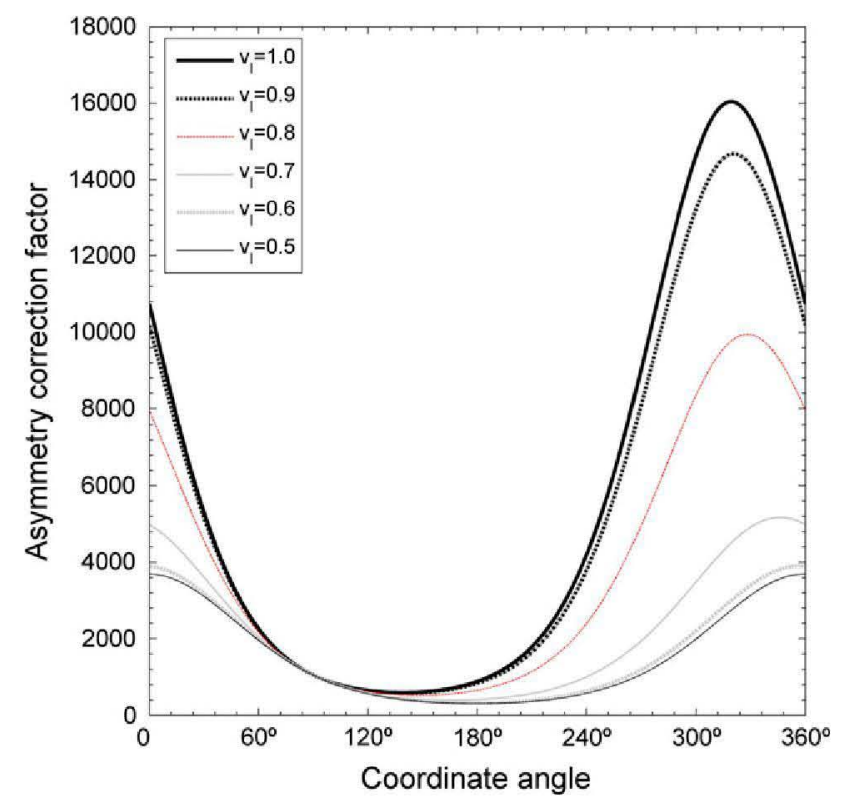

Fig. 5. Asymmetry correction factor as function of the coordinate angle and the relative initiation velocity $\left(v_{1}\right)$.

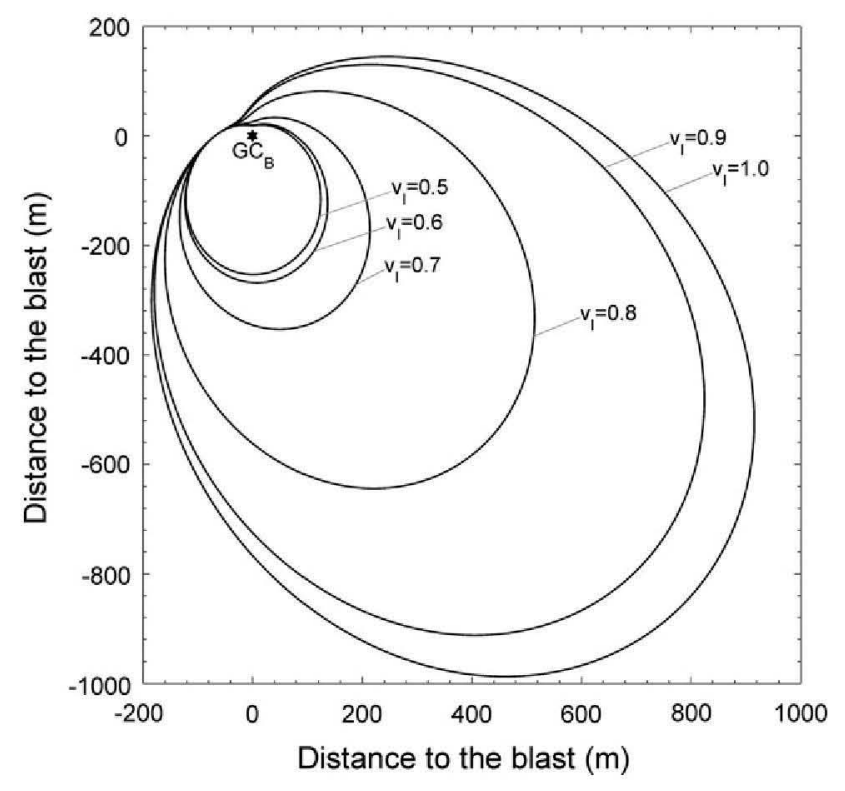

Fig. 6. Effect of blast sequence on the contours of 89.3 Pa peak overpressure $\left(G C_{B}\right.$ is the gravity centre of the blast).

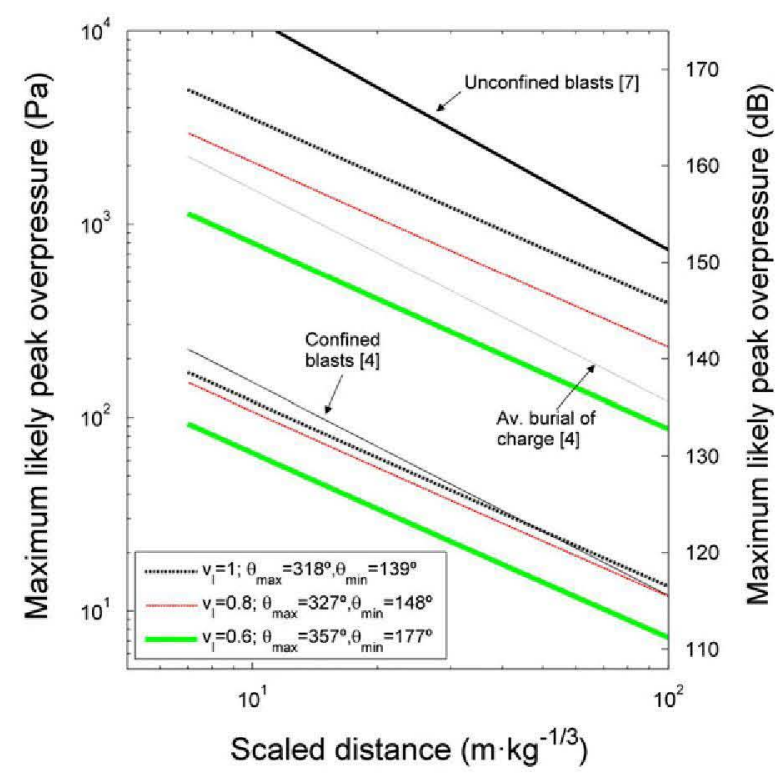

Fig. 7. Maximum likely overpressures as function of the scaled distance and relative initiation velocity of the blast $\left(\nu_{3}\right)$. Lines drawn correspond to the propagation paths at which pressure is maximum and minimum. The polar angles of these paths, $\theta_{\max }$ and $\theta_{\min }$ are given in the legend.

level from our model. It is given in Fig. 7 as a function of the scaled distance; for each initiation velocity, lines of maximum and minimum overpressure $P_{\max }$ (corresponding to polar angles $\theta_{\max }$ and $\theta_{\min }$, respectively, given in the legend of Fig. 7) are plotted. As a matter of comparison, propagation laws from blasting handbooks by ISEE [4] and Hustrulid [7] are also shown in Fig. 7.

\section{Conclusions}

Peak overpressure is a useful indicator of the damage and disturbance that airblast may produce nearby a blasting site. This work provides a model for such pressure from blasts with one free face in which the blastholes are delayed in a typical quarry blasting 
practice, from the hole in one end of the block towards the other end. The peak overpressure is obtained as the product of a classical scaled distance function times a directional correction factor. The scaled distance law is based on the mass of explosive per delay. The directional correction factor considers the influence of:

- Bench face: it amplifies overpressure at the bottom level (i.e. in front of the rock movement) and attenuates it at the top (i.e. behind the rock movement) through a cosine function of the polar angle or azimuth of the position of interest.

- Blast delay: it amplifies blast waves in the direction of the initiation sequence if the velocity of initiation exceeds half the sound speed, increasing the amplitude up to an initiation velocity in the range of the speed of sound.

Blasting data and airblast measurements from 122 records in 40 blasts and one single shot made in rocks with low to very low strength are used to build the model. The explosive mass in a delay varied from 21.3 to $284 \mathrm{~kg}$, and the initiation velocity of the blast ranged between $67 \mathrm{~m} / \mathrm{s}$ and $383 \mathrm{~m} / \mathrm{s}$. Airblast was measured with linear type microphones around the blasted blocks at distances from the blast of $45-394 \mathrm{~m}$. The measured peak overpressures ranged from 482 to 6 Pa with a relative expanded uncertainty of $13.1 \%$. The model explains $87 \%$ of the variance in the logarithm of overpressure and is statistically meaningful. No difference in the goodness of the fit is observed when explosive energy is used instead of explosive mass. The accuracy in overpressure prediction is $32 \%$. The model has been validated from data monitored in five new blasts. The mean absolute relative error is $22.6 \%$, and the corresponding relative prediction errors are within the errors obtained from the model building data set.

The model is used to derive upper prediction bounds at a $95 \%$ confidence level of peak overpressure as function of the scaled distance, initiation velocity and propagation paths. The corresponding plots can be used to assess the range of maximum blast overpressure levels expected in a particular blast design. These values are useful to evaluate whether the model can be applied in a different site.

\section{Acknowledgments}

Cementos Portland Valderrivas and Saint Gobain Placo Iberica are acknowledged for their permission and support to carry out the field work in El Alto and Monte Espartinas, respectively. The experimental work in El Alto has been partially funded by the European Union under Contract No. G1RD-CT-2000-00438, "Less Fines Production in Aggregate and Industrial Minerals Industry". The collection of data in Monte Espartinas quarry has been partially funded by MAXAM, which support is gratefully acknowledged. Special recognition is due to Alberto Gómez, Javier Gutierrez and Javier Quemada for their enthusiastic cooperation in the data gathering. We would like to thank the production staff in El Alto and Monte Espartinas and the students that contributed to the field work.

\section{References}

[1] Persson PA, Holmberg R, Lee ]. Rock blasting and explosives engineering. Boca Raton: CRC Press; 1994. p. 375-86, 515.

[2] Siskind DE, Stachura VJ, Stagg MS, Koop JW. Structure response and damage produced by airblast from surface mining. United States Bureau of Mines Report of Investigation $8485 ; 1980$.

[3] Mohanty B. Physics of explosions hazards. In: Beveridge A, editor. Forensic investigation of explosions. London: Taylor and Francis; 1998. p. 22-32.

[4] International Society of Explosives Engineers. Blasters' handbook. 17th ed. Ohio: International Society of Explosives Engineers, Cleveland; 1998. p. 62644.

[5] Marchand KA. Load definition. In: Conrath EJ, editor. Structural design for physical security: state of the practice. Reston: Structural Engineering Institute, American Society of Civil Engineers; 1999. p. 2.7-.18.

[6] Kuzu C, Fisne A, Ercelebi SG. Operational and geological parameters in the assessing blast induced airblast-overpressure in quarries. Appl Acoust 2008;70(3):404-11

[7] Hustrulid W. Blasting principles for open pit mining - general design concepts vol. I. Boca Raton: CRC Press; 1999. p. 281-5.

[8] Griffiths M], H Oates JA, Lord P. The propagation of sound from quarry blasting. J Sound Vib 1978;291:358-70

[9] Moore AJ, Evans R, Richards AB. An elliptical airblast attenuation model. In: Proceedings of the 4 th international symposium on rock fragmentation by blasting-fragblast 4, Vienna; July 1993. p. 247-52.

[10] Richards $\mathrm{AB}$, Moore AJ. Airblast design concepts in open pit mines. In: Proceedings of the 7 th international symposium on rock fragmentation by blasting-fragblast 7, Beijing, China; August 2002. p. 553-61.

[11] Rudenko D. Airblast an often overlooked cause of structural response. In: Proceedings of the 28th annual conference on explosives and blasting technique, vol. 2, Las Vegas: February 2002. p. 153-66.

[12] Domingo JF. Análisis de la onda aérea producida por voladuras en banco en el campo cercano. PhD thesis, Universidad Politécnica de Madrid; 2007.

[13] Egorov MG. Blast design optimization to minimize effect of airblast. In: Proceedings of the 22nd annual conference on explosives and blasting technique, vol. 1, Orlando; February 1996. p. 286-93.

[14] Rosenthal MF, Morlock GL. Blasting guidance manual. Office of Surface Mining Reclamation and Enforcement, United States Department of the Interior; 1987

[15] Sanchidrián JA, Segarra P, Burden S, López LM. On the use of rock constants in bench blast design methods. In: Proceedings of the 7 th international symposium on rock fragmentation by blasting-fragblast 7, Beijing; August 2002. p. 396-405.

[16] African Explosives and Chemical Industries. The design of surface blasts, serie 2, African Explosives and Chemical Industries, Technical Bulletin 41; 1986.

[17] Ash RL. The mechanics of rock breakage, parts I-IV. Pit Quarry 1963;56(2-5). p. $98-100,118-22,126-31,109-18$.

[18] Dowding CH. Construction vibrations. In: Dowding, editor; 2000. p. 204-7.

[19] International Society of Explosives Engineers. Performance specifications for blasting seismographs. <www.isee.org./FPvibrationsection.htm> [15.01.2000].

[20] International Society of Explosives Engineers. ISEE field practice guidelines for blasting seismographs. 2009 Edition; 2009.

[21] Taylor BN, Kuyatt C. Guidelines for evaluating and expressing the uncertainty of NIST measurement results. National Institute of Standards and Technology Technical Note 1297; 1994.

[22] Snell CH, Oltmans DL. A revised empirical approach to airblast prediction. US army engineer waterways experiment station, explosive excavation research office report no. 39; 1971. p. 44-51.

[23] Konya C]. Blast design. Montville: Intercontinental Development; 1995. p. 845.

[24] Kutner $\mathrm{MH}$, Nachtsheim CJ, Neter J. Applied linear regression models. 4th ed. Singapore: McGraw-Hill; 2004. p. 278-89, 406-12. 